\title{
Bilateral central scotomata due to intracranial tumour
}

\author{
N. G. R. PAGE AND M. D. SANDERS \\ From the National Hospitals for Nervous Diseases, Queen Square, London WC1
}

SUMMARY Bilateral centrocaecal scotomata have been recognised as a sign of intrinsic optic nerve disease, usually associated with hereditary optic neuropathy, and nutritional or toxic amblyopias. This report describes four patients with central scotomata due to intracranial masses, three of whom recovered after surgical intervention. The clinician should be alerted to the association in patients with headaches, other neurological signs, and central visual loss.

A central scotoma is characteristic of optic nerve disease and found concomitantly with reduced visual acuity, reduced colour vision, an afferent pupil defect, and pallor of the optic disc. Macular disease may cause a central field defect which may be present bilaterally, but metamorphopsia, abnormal photostress, and normal pupils in conjunction with fundus details seen on fluorescein angiography will usually allow an accurate diagnosis.

When central visual loss is unilateral, painless, and progressive, a compressive optic neuropathy will be suspected. However, the vast majority of bilateral optic neuropathies are due to 'toxic,' 'inflammatory,' or hereditary causes, and compression is not usually suspected. Typically, compressive lesions of the anterior visual pathways are unilateral or, if bilateral, very asymmetric, with late involvement of the second eye, and then signs of chiasmal involvement. The diagnosis of a toxic or nutritional amblyopia may be presumptive, particularly with a reticent patient in whom field charting may, with difficulty, reveal discrete symmetrical centrocaecal scotomata.

We have recently seen four patients presenting with visual failure and bilateral central scotomata. In each case this was caused by an expanding intracranial tumour.

\section{Case reports}

CASE 1

A 65-year-old woman was admitted for investigation of bilateral visual loss. Initially she had noted progressive blurring of vision in the right eye for a year, and during that period a small horseshoe retinal tear

Correspondence to Dr N. G. R. Pagc, MRC Neuro-Otology Unit, Institute of Neurology, National Hospital, Queen Square, London
WC1N 3BG. in the periphery was repaired. In the weeks before admission she had noticed increasing central mistiness in the left eye, with inability to read a newspaper. There was no ocular pain or headache and no other specific complaints, but on questioning she admitted to loss of smell for about a year. She was a nonsmoker, did not consume alcohol, and had an adequate diet.

She was fit and alert, with abnormalities confined to the visual and central nervous systems. Corrected vision in the right eye was counting fingers at 1 metre, near vision less than $\mathrm{N} 48$, with absent colour perception; in the left eye $6 / 24, N 36$, with gross reduction in colour perception. There was a mild anisocoria (right $3.5 \mathrm{~mm}$, left $2.5 \mathrm{~mm}$ ) but with equal reaction to light and near. There were no orbital signs, and eye movements and slit-lamp examination were normal. Visual field testing revealed bilateral central scotomata, larger and denser on the right (Fig. 1a). The right optic disc showed slight pallor and the left was normal (Fig. 1b). A satisfactory repair of the right retinal detachment was noted inferotemporally and no macular changes were seen. There was no perception of smell in either nostril and the rest of the cranial nerves were normal. Mild pyramidal signs were present in the left arm and leg, with hyperreflexia and an extensor plantar response with normal power and tone.

Investigations. Visual evoked potentials confirmed bilateral visual failure, with no response to pattern reversal stimulation on the right and a low voltage, broad, delayed wave form on the left. The plain skull $x$-ray was normal, and computerised scanning revealed a uniformly enhanced mass, $7 \mathrm{~cm}$ in diameter, arising from the floor of the anterior cranial fossa (Fig. 1c). Carotid angiography confirmed a large meningioma arising from the olfactory groove.

Operation (Professor L. Symon). Right frontal 


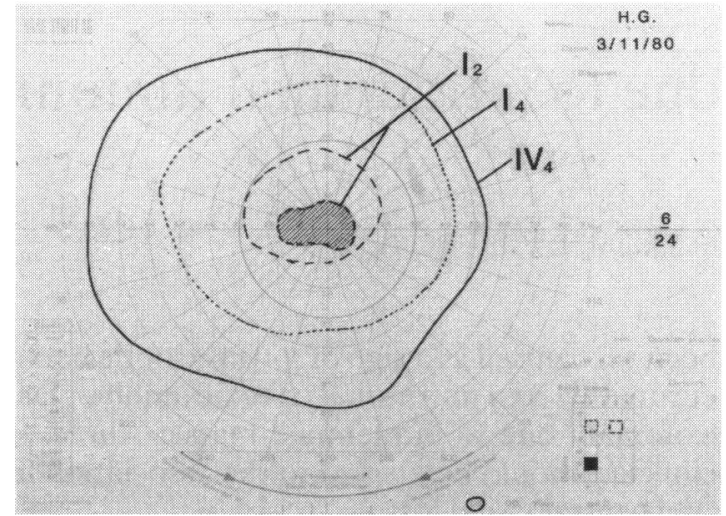

Fig. la Case 1. Goldmann visual fields.

craniotomy was performed with removal of the meningioma. The right optic nerve was noted to be compressed. Furthermore, a tongue of tumour extended on to the jugum sphenoidale to the suprasellar region and entered the right optic canal. Having no real attachment within the optic canal, this was hooked out. The optic nerves were short. The optic chiasm was seen and not involved by tumour.

The patient was slow to recover, not becoming fully alert until 10 days postoperatively. By that time acuity had improved to $6 / 6, \mathrm{~N} 6$, in the right eye and $6 / 6, \mathrm{~N} 4 \cdot 5$, in the left. Colour vision was normal in the left eye. The central scotomata had resolved completely in the left eye with only slight depression of the $I_{4}$ isoptre inferonasally in the right visual field. At

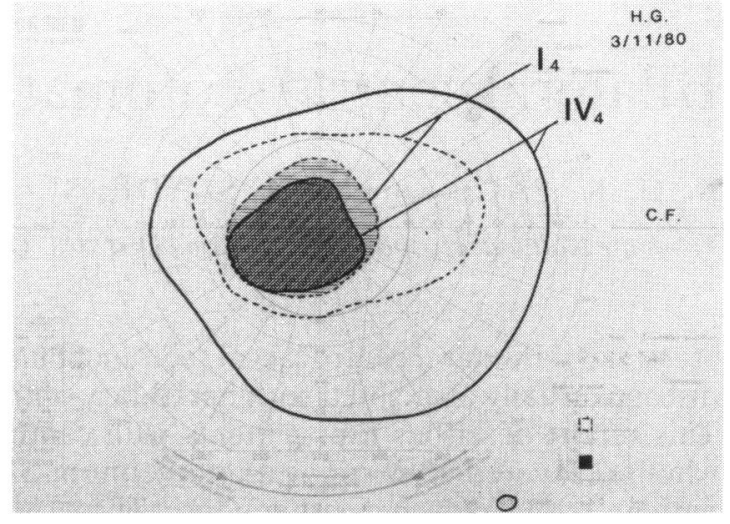

one-year follow-up visual acuity was $6 / 5$ bilaterally, with completely normal visual fields on Goldmann and Friedman perimetry, and normal optic discs.

Histology of the tumour was that of a meningioma.

Comment. The asymmetrical development of central scotomata was due to a large subfrontal meningioma. Headache and definite neurological signs were present on admission. A small nubbin of tumour entered the optic canal on the most affected side. Removal of the tumour led to complete recovery.

\section{CASE 2}

A 36-year-old man was admitted in December 1979 for investigation of bilateral visual loss and headache.
Fig. 1b Case 1. Normaloptic discs.
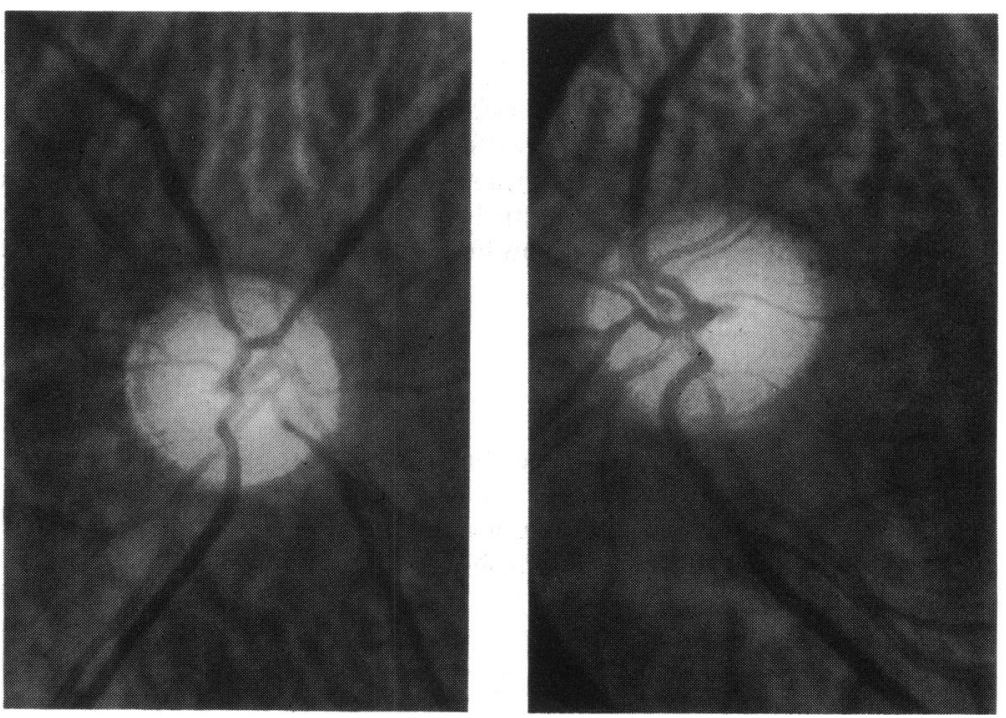


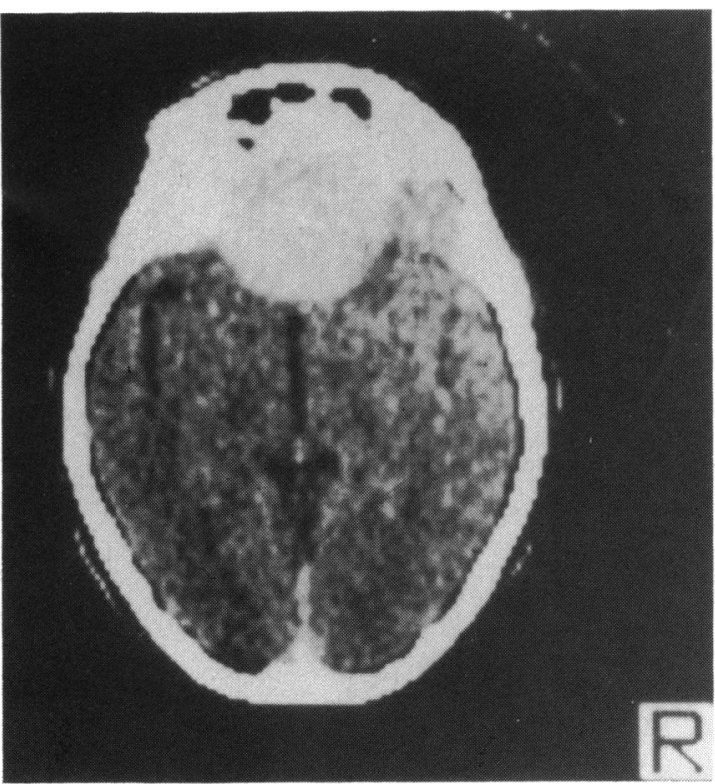

Fig. 1c Case 1. Enhanced CT scan showing a meningioma arising from the floor of the anterior cranial fossa.

Bifrontal headaches had been occurring with increasing frequency for two years. These were suggestive of raised intracranial pressure, being maximal on waking, worsened by stooping, and accompanied by nausea and occasional vomiting. Treatment of migraine had partially relieved this headache. He became aware of visual deterioration six months before admission. This was initially improved by spectacles, but for four months he had been unable to read small print. The left eye was involved first, and he had latterly noted central loss with preservation of peripheral vision. The day before admission he had a syncopal attack, but there were no other specific complaints.

Examination revealed a passive and apathetic man who was otherwise alert, with normal higher functions. Smell sensation was impaired bilaterally; he was aware of but unable to recognise test smells. Visual acuity was $6 / 18, \mathrm{~N} 8$, on the right and counting fingers at 1 metre, $\mathrm{N} 48$, on the left, with marked impairment of colour appreciation bilaterally. There was a left relative afferent pupil defect. Eye movements and slit-lamp examination were normal. Visual fields showed bilateral central scotomata (Fig. 2a). The optic discs were judged to be within normal limits (Fig. 2b). There were no other abnormalities in the central nervous system, and general examination was normal.

Investigations. Skull $x$-ray showed an expanded sella turcica and erosion of the lamina dura and floor of the anterior fossa with flecks of calcification in the inferior frontal region. Computerised scanning demonstrated an extensive bifrontal glioma extending posteriorly into the region of the corpus callosum, with cysts in both frontal lobes (Fig. 2c). Bilateral carotid angiography confirmed the intrinsic mass, which extended more posteriorly on the left.

Operation (Mr N. Shannon). Left frontal craniotomy revealed extensive gelatinous tumour tissue in the left frontal lobe, and a left frontal lobectomy was performed. Tumour tissue was then sucked out of the genu of the corpus callosum. A second large cyst was encountered in the right frontal lobe, the walls of which were cleared with macroscopic removal of tumour, It was pessible to see both optic nerves being compressed by tumour, but the chiasm was not visualised. There was no evidence of direct infiltration of the optic nerves or chiasm. Histology of the tumour was consistent with a gemistocytic astrocytoma with some microcystic degeneration.
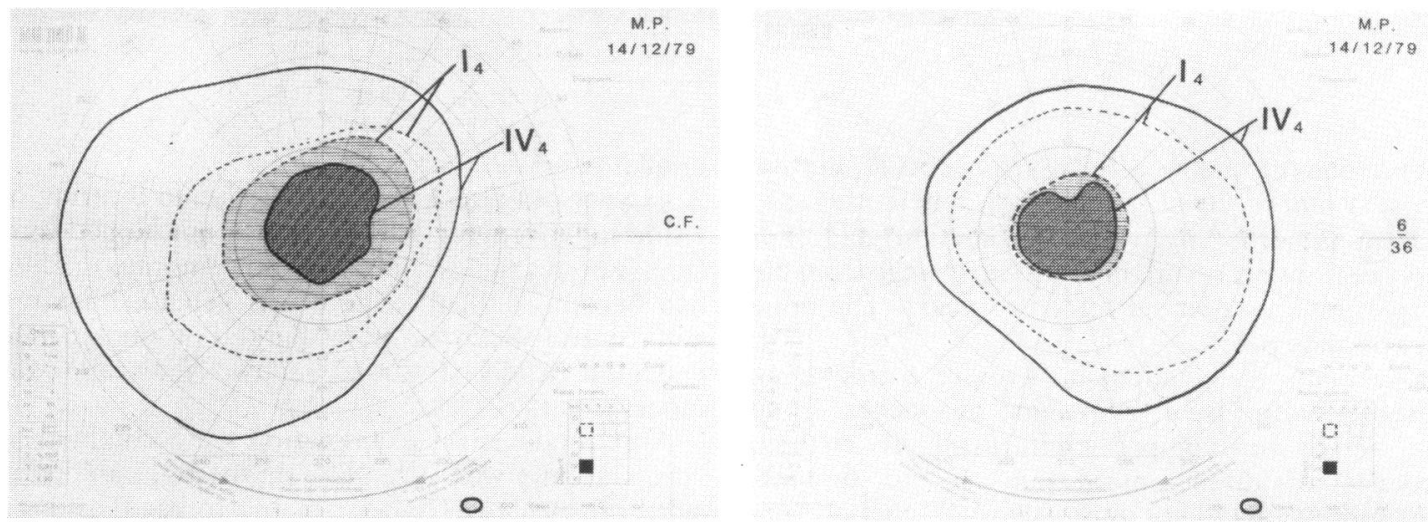

Fig. 2a Case 2. Visual fields. 
Fig. 2b Case 2. Photograph and
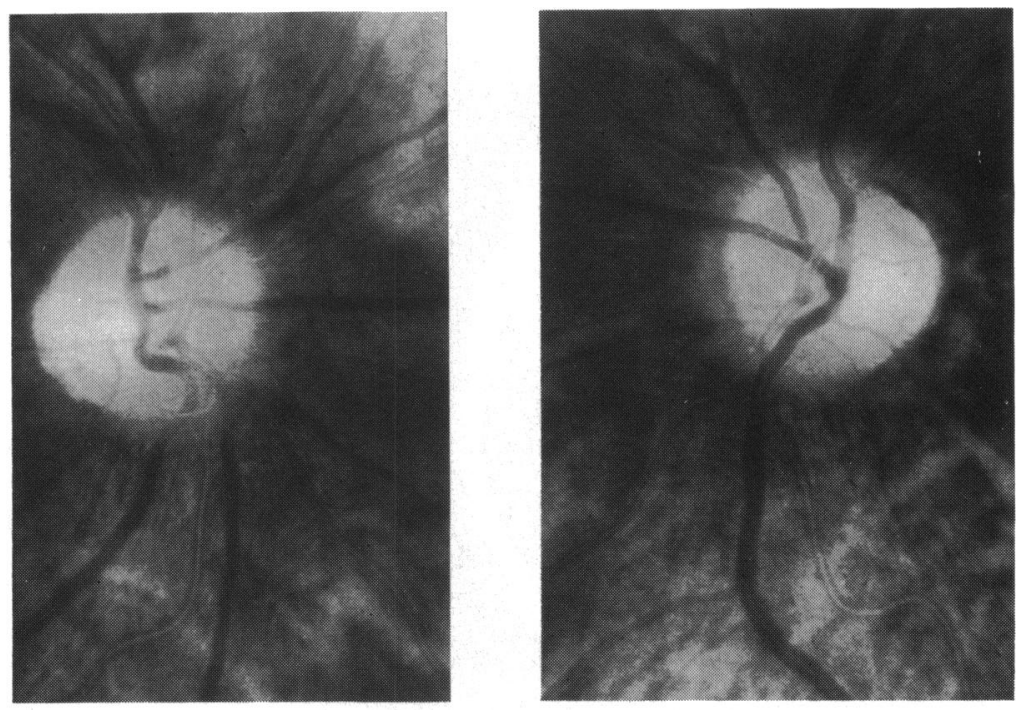

fluorescein angiogram showing normal optic discs and choroidal striae (arrowed).
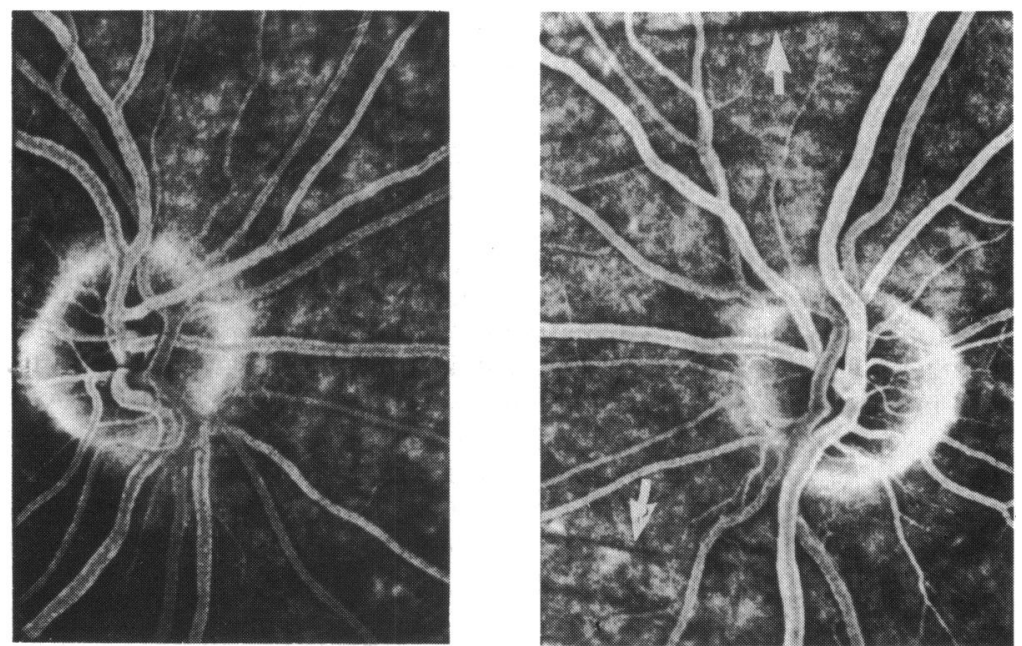

The patient made a satisfactory postoperative recovery and received radiotherapy, chemotherapy, and immunotherapy. Visual function did not improve, however, and there was no change from the preoperative assessment after two years. The optic discs became pale.

Comment. A malignant frontal astrocytoma presented with visual failure and headaches. Long optic nerves were compressed intracranially, with no evidence of direct infiltration by the tumour. Decompression did not improve visual function, and the discs became atrophic.
CASE 3

A 47-year-old Greek banker noted mild blurring of vision in November 1981. This was not helped by a change of spectacles, and within three months reading had become difficult. There was general blurring, with central shadows, more marked on the left. He had mild headaches for about two years and was otherwise fit.

Abnormalities on examination were confined to vision. Acuity was $6 / 18, \mathrm{~N} 24$, on the right and $6 / 38$, $\mathrm{N} 36$, on the left. He was unable to read Ishihara colour plates. Goldmann fields showed central 


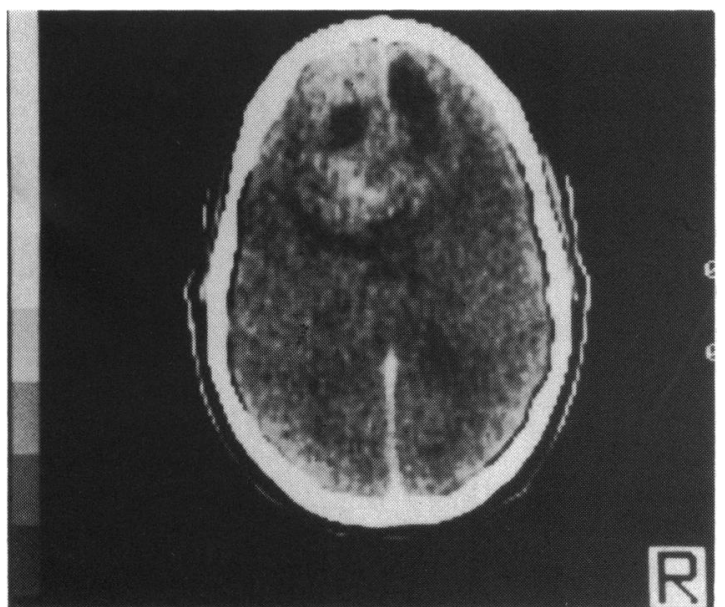

Fig. 2c Case 2. Enhanced CT scan demonstrating a bifrontal cystic glioma.

scotomata to the $I_{4}$ target in each eye (Fig. 3a). Intraocular pressures and ocular movements were normal, and the optic discs were of good colour (Fig. 3b).

Investigations. CT scan (Fig. 3c) showed an enhancing mass within the pituitary fossa with significant suprasellar extension, particularly to the right. Bilateral carotid angiography confirmed the presence of the mass but with no pathological correlation.

Operation (Mr Norman Grant). An uneventful transphenoidal hypophysectomy was performed in July 1982.

Histology of the material removed was that of a chromophobe pituitary adenoma.

The patient made a satisfactory postoperative recovery. Ophthalmological assessment at 8 days was unchanged from the preoperative findings, but two months later vision had improved. He could now see $6 / 6$, N5, with each eye, with normal colour vision and fields. The optic discs remained normal.

Comment. A patient with a chromophobe adenoma had the unusual visual presentation of bilateral central scotomata. Following hypophysectomy full recovery occurred over two months.

\section{CASE 4}

A 38-year-old engineer noticed a change in vision in October 1981. Initially peripheral vision seemed impaired, although he felt acuity was not perfect. Visual failure progressed, particularly for reading. By January 1982 he could read only with a magnifying glass, and by then distance vision seemed quite abnormal. He could not appreciate colours normally. Vision seemed slightly better in dull illumination; there were no positive visual phenomena. At this time he developed troublesome bifrontal headaches that were exacerbated by stooping or coughing. There were no symptoms to suggest endocrine disease or multiple sclerosis.

He had no serious past illnesses, ate a good diet, had never smoked, and admitted to only very limited alcohol consumption. He had worked in the Middle East three years previously.

Examination showed an anxious, introspective, but sensible man with abnormalities confined to the visual sensory system. There was 6 dioptres of myopia. With correction, acuity was only $3 / 60$ on the right and $1 / 60$ left, with inability to read any near test types or colour plates; pupil reactions were symmetrical. Visual field charting showed generalised depression, with discrete bilateral central scotomata (Fig. 4a).

The optic discs were judged normal for his skin colour and the degree of myopia.

Investigations. Plain skull $x$-rays were normal, with no abnormal calcification. Computerised scanning
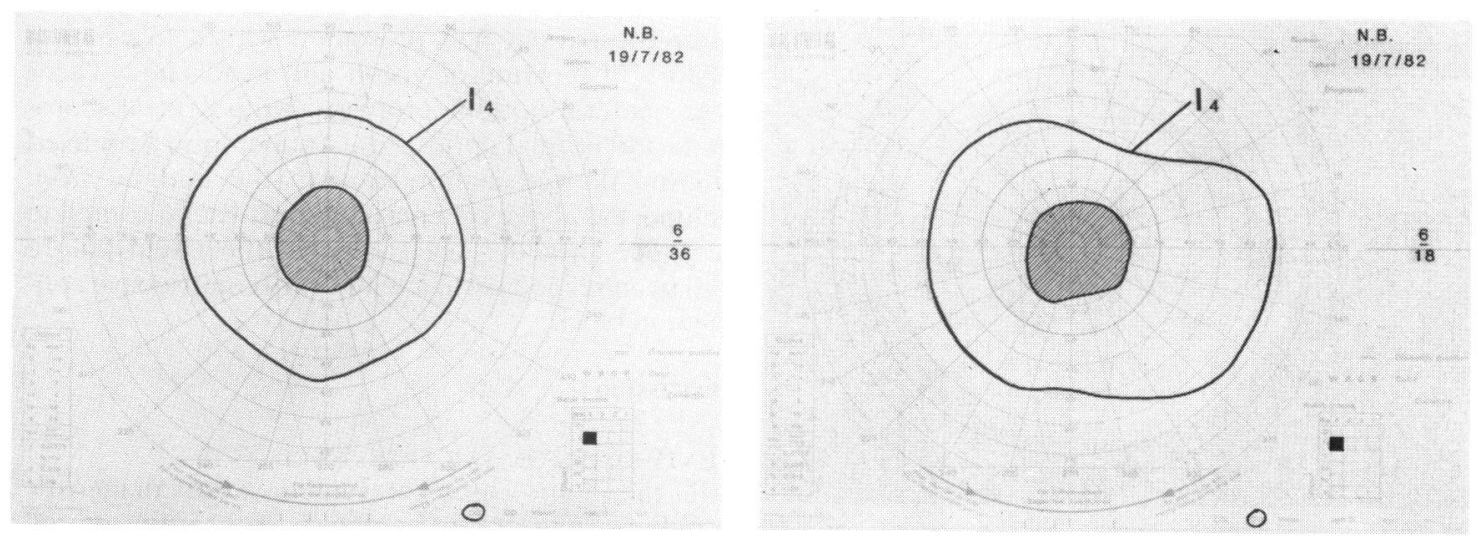

Fig. 3a Case 3. Visual fields. 
Fig. 3b Case 3. Normal optic discs.
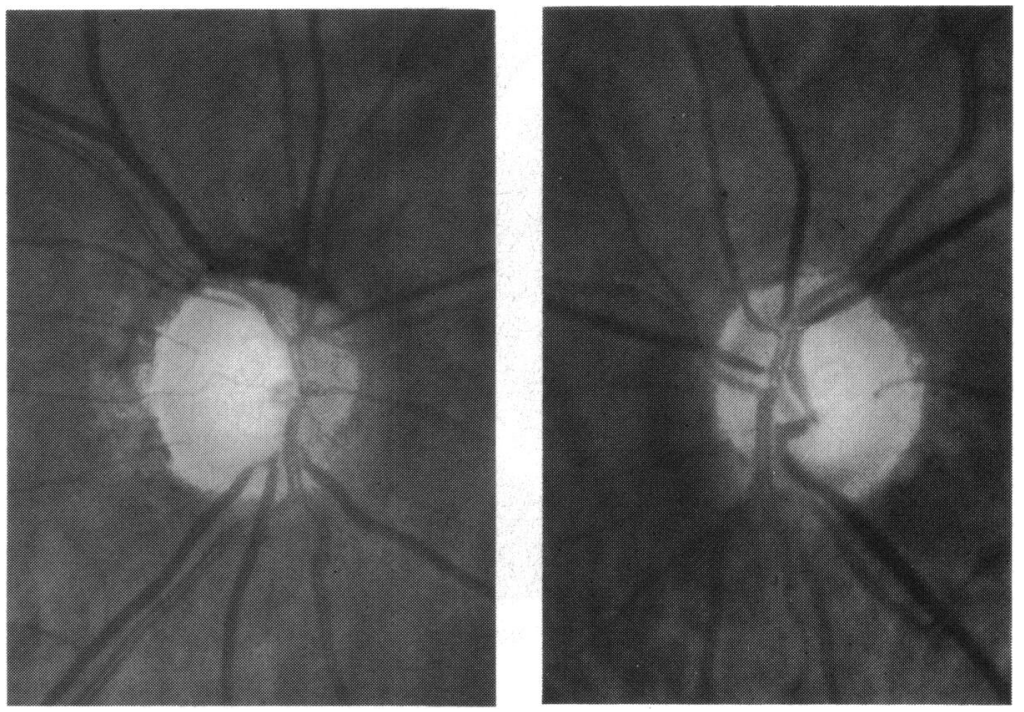

showed a well circumscribed low-density lesion in the suprasellar cistern which did not enhance (Fig. 4b). The location of this mass was confirmed by air encephalography, which also showed minimal symmetrical dilatation of the lateral ventricles (Fig. 4c).

Carotid angiography did not show any abnormal vasculature or aneurysm and preoperative endocrine assessment was normal. No pattern visual evoked responses could be recorded. Flash VEP's were grossly abnormal, but symmetrical.

Operation (Professor L. Symon). A right frontal craniotomy was performed on 17 March 1982. The

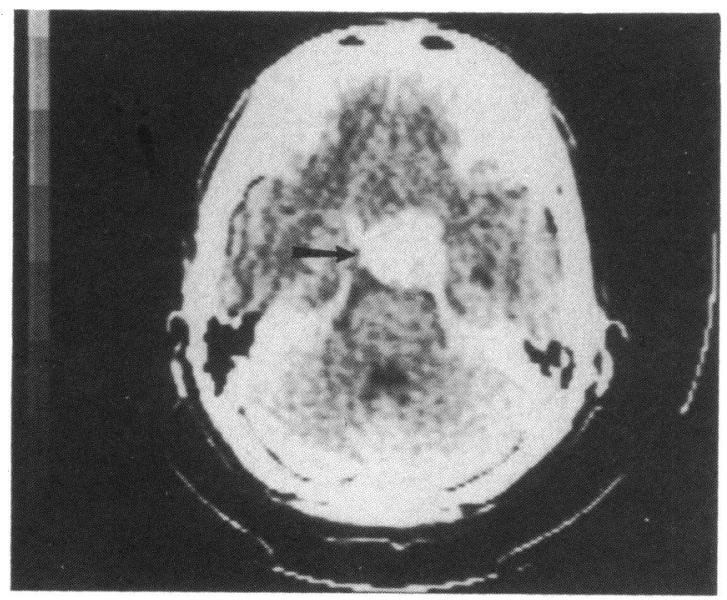

Fig. 3c Case 3. Enhanced CT scan showing a suprasellar mass (arrowed). operative findings were of a prefixed optic chiasm with only a millimetre between the chiasm and the jugum. There was a stout-walled, yellowish cyst lying above and behind the chiasm compressing the floor of the third ventricle. The contents were evacuated, and the wall of the cyst was removed by dissection. Histology proved this to be a cystic craniopharyngioma.

He made a good postoperative recovery, accompanied by transient diabetes insipidus. Ophthalmological assessment was performed six days postoperatively. Visual acuity was $6 / 5$ in each eye. In the right he could read 5 out of 10 Ishihara plates and 8 out of 10 in the left. Visual fields showed marked improvement, with disappearance of the central scotomata and expansion of the peripheral fields. By two months postoperatively his vision was judged normal. The optic discs were also normal.

Comment. A craniopharyngioma was removed after the patient had presented with a five-month history of blurring of vision and headaches. There was bilateral optic neuropathy, with central scotomata and normal optic discs. At operation a prefixed chiasm allowed compression in the midline from behind and above by a hard tumour. Rapid complete recovery ensued, suggesting that the visual failure had been secondary to a temporary compressive conduction block.

\section{Discussion}

FEATURES OF CASES PRESENTED

All the four cases presented were diagnostic problems, and ophthalmologists were often misled by the normality of the optic discs. Visual loss was 


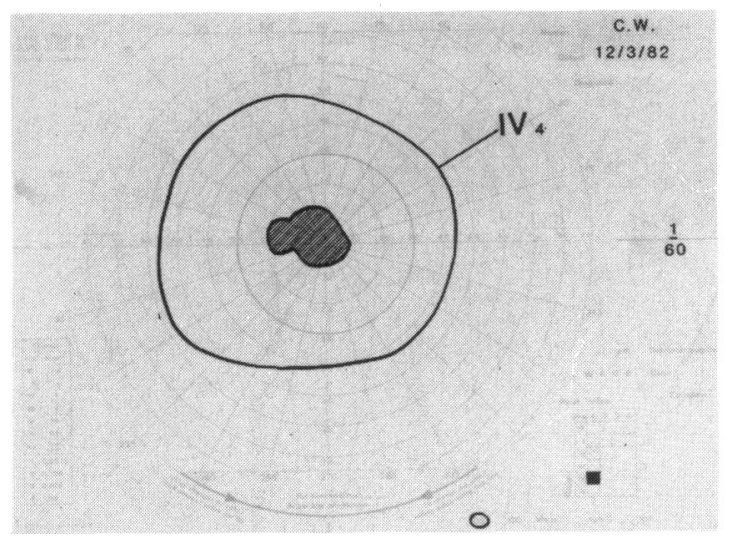

Fig. 4a Case 4. Visual fields.

bilateral in three cases and initially unilateral in one case (olfactory groove meningioma). Initial diagnoses included migraine, optic neuritis, and toxic/nutritional amblyopia, and the first case was further confused diagnostically by a retinal detachment.

Symptoms suggestive of intracranial optic nerve compression included headaches, usually nonspecific, though accompanied by nausea and vomiting in one patient. Ocular pain was not a symptom. In one case the only neurological sign was loss of smell. Thus the early recognition of this condition is dependent solely on the skill of the ophthalmologist in recognising the organic nature of the field defect and arranging the appropriate CT scans. A review of the various disorders that may present in this way has been published elsewhere. ${ }^{\prime}$

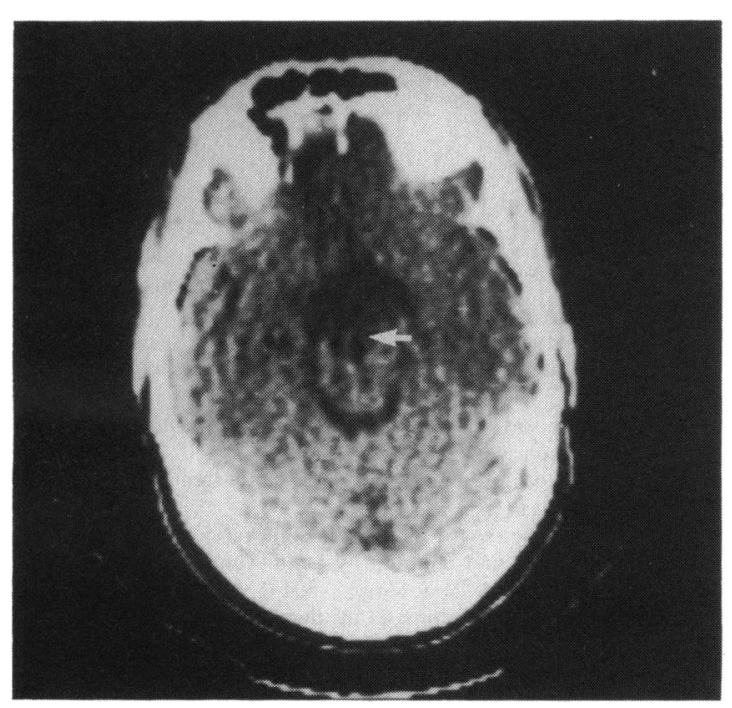

Fig. 4b Case 4. CT scan showing cystic suprasellar lesion.

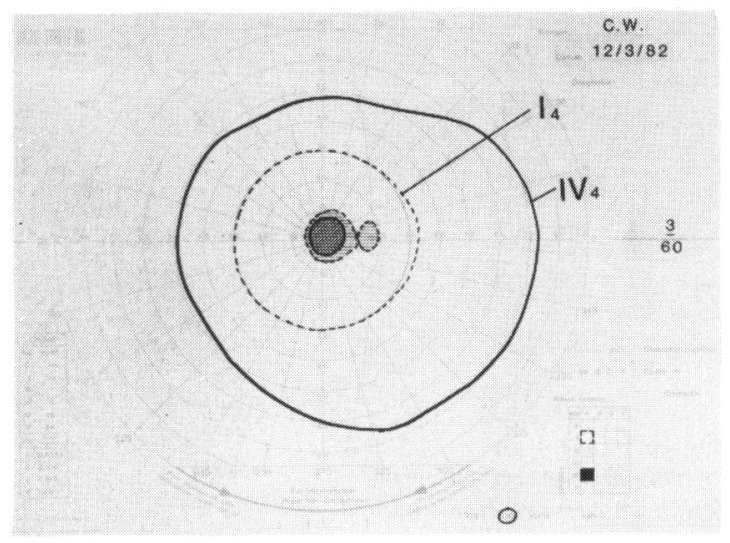

DIFFERENTIAL DIAGNOSIS OF BILATERAL OPTIC NEUROPATHY

(a) Centrocaecal scotomata. In the presence of a normal macula, bilateral central scotomata usually suggests intrinsic optic nerve disease. The majority of these cases are due to hereditary factors or have nutritional or toxic causes.

Acute optic neuritis may be bilateral in adults and is usually associated with neurological signs in multiple sclerosis, though bilateral chronic demyelination is a recognised entity. More often the second eye has been affected after an interval. Leber's optic neuropathy may also present acutely in the same age group, and a positive family history will be the distinguishing feature.

Ischaemia of the retrobulbar portion of the optic nerves is a factor in some types of bilateral optic neuropathy. Subacute or delayed radiation necrosis, usually following postoperative radiation of sella tumours, ${ }^{2.3}$ and post-traumatic optic neuropathy, ${ }^{4}$ may have an ischaemic basis.

(b) Compressive causes. Subfrontal gliomas and meningiomas cause visual disturbances among their earliest manifestations, ${ }^{5}$ but unilateral visual loss with optic atrophy and much later involvement of the second eye and chiasmal compression is the rule. Jefferson" laid particular stress on this asymmetry, with the production of a Foster-Kennedy syndrome. Basal lesions of the frontal lobe cause visual loss with central scotomata and 'choked discs' but rarely bilaterally. ${ }^{7}$

Central field defects with pituitary adenomas have been infrequently reported. Henderson ${ }^{*}$ described bilateral central scotomata in $2.5 \%$ of 243 patients, and Hirsch and Hamlin" reported central visual loss in 6 out of 59 cases, but it is not clear whether any of these were bilateral. Kelly"1 described bilateral central and hemianopic scotomata with pituitary adenomas. 
Fig. 4c Case 4. Air encephalogram confirming the lesion which is deforming the 3 rd ventricle (arrowed).

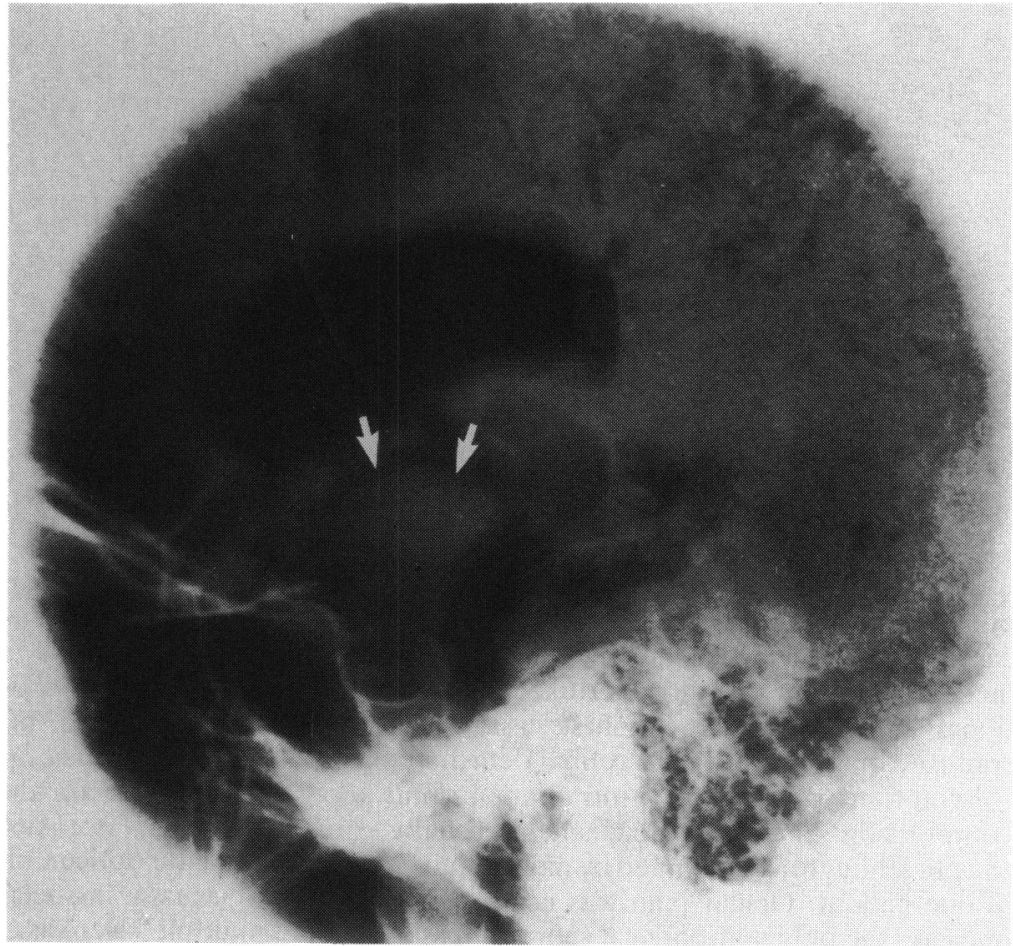

Craniopharyngomas usually cause bitemporal field defects. Wagener and Love ${ }^{11}$ described 29 patients and later Ross Russell and Pennybacker ${ }^{12}$ discussed the clinical and ocular findings in a further 16 patients with operatively proved craniopharyngioma. There were no cases of bilateral scotomata in these groups, though there were four bitemporal scotomata. Earlier one out of four cases cited by Cushing ${ }^{1.3}$ had bilateral central scotomata.

Suprasellar meningiomas very rarely cause bilateral visual failure with central scotomata; none occurred in a series of 83 cases $^{1+}$ and one example was described by Rucker and Kearns. ${ }^{15}$

Meningeal carcinomatosis with compressive cuffing and perhaps infiltration frequently involves both nerves with progressive visual loss. ${ }^{10}$ Bilateral optic neuropathy will be accompanied by orbital signs when compression at the apex occurs in dysthyroid eye disease.

(c) Miscellaneous. Infiltrating optic nerve gliomas or hamartomas, particularly when arising in the intracranial portion of the nerve or chiasm, ${ }^{17}$ cause bilateral loss of vision, and central scotomata may be a feature. In contrast, optic nerve sheath meningiomas involve the second eye late in the natural history. ${ }^{18} \mathrm{~A}$ normal appearance of the discs is unlikely with these tumours.
Direct infiltration can occur from primary or secondary nasopharyngeal or sphenoid sinus malignancies. Optochiasmatic arachnoiditis, lymphoreticular infiltration, and syphilitic optic atrophy are further causes of bilateral visual loss.

The authors thank Dr R. W. Ross Russell for allowing them to report details of the patient under his care (case 3).

Dr Page is supported financially by the Smith Charity.

\section{References}

1 Moseley IF, Sanders MD. Computerized tomography in neuroophthalmology. London: Chapman and Hall, 1982.

2 Rosengren B. Two cases of atrophy of the optic nerve after previous roentgen treatment of the chiasmal region and the optic nerves. Acta Ophthalmol (Kbh) 1958; 36: 874-8.

3 Harris JR, Levene MB. Visual complications following radiation for pituitary adenomas and craniopharyngiomas. Radiology 1976; 120: $167-71$.

4 Ticho U, Fcinsod M. Traumatic optic ncuritis. Ann Ophthalmol 1973: 5: 430-2.

5 Huber A. Eyc signs and symptoms in brain tumours. $S$ Afr Arg Oftalmol 1979; 6: 31-47.

6 Jefferson G. The Doyne lecture: on compression and invasion of the optic nerves and chiasma by neighbouring gliomas. Trans Ophthalmol Soc UK 1945; 65: 261-304

7 Lillic WI. Ocular phenomena produced by basal lesions of the frontal lobe. JAMA 1927; 89: 2(199-103.

8 Henderson WR. Pituitary adenomata; follow up study of surgical results in 338 cases (Dr Harvey Cushing's scries). BrJ Surg 1939; 26: $811-921$. 
9 Hirsch O, Hamlin H. Fatc of visual ficlds and optic discs in pituitary tumours. Am J Ophthalmol 1954; 37: 880)-5.

10 Kelly RE. Lesions of the optic chiasm due to compression. Trans Ophthalmol Soc UK 1962; 83: 149-64.

11 Wagener HP. Love JG. Fields of vision in cases of tumour of Rathke's pouch. Arch Ophthalmol 1943: 29: 873-87.

12 Russell RWR. Pennybacker JB. Craniopharyngioma in the elderly. J Neurol Neurosurg Psychiatry 1961; 24: 1-13.

13 Cushing $\mathrm{H}$. The chiasmal syndrome of primary optic atrophy and bitemporal ficld defects in adults with normal sella turcica. Arch Ophthalmol 1930; 3: 505-51, 7()4-35.

14 Finn JE, Mount LA. Meningiomas of the tuberculum sellac and planum sphenoidalc: a review of 83 cases. Arch Ophthalmol 1974: 92: 23-7.

15 Rucker CW. Kearns TP. Mistaken diagnoses in some cases of meningioma. Am J Ophthalmol 1961: 51: 15-9.

16 Terry TL. Dunphy EB. Metastatic carcinoma in both optic nerves simulating retrobulbar neuritis. Arch Ophthalmol 1933: 10: $611-4$.

17 Spoor TC, Kennerdell JS, Martinez AJ, Zorub D. Malignant gliomas of the optic nerve pathways. Trans Am Ophthalmol Soc 1972; 70: 490-528.

18 Hart WM Jr, Burde RM, Klingele TG. Perlmutter JC. Bilateral optic nerve sheath meningiomas. Arch Ophthalmol 1980; 98: $149-51$. 